\title{
Incomplete Coaptation
}

National Cancer Institute

\section{Source}

National Cancer Institute. Incomplete Coaptation. NCI Thesaurus. Code C63090.

Problem associated with the heart valve leaflet not closing properly. 